\title{
Unmanned Aerial Vehicle Path Planning using Bat Algorithm
}

\author{
S. Aicevarya Devi, C. Vijayalakshmi
}

\begin{abstract}
Unmanned Aerial Vehicles (UAV) was introduced after World War II. In 1980's UAV consider as important weapon system. Initially UAV needs initial position and target position. In this paper bat algorithm is proposed with mixed objective constraints which helps in directing the UAV. The process is initialized by generating the initial population of bat. Then by updating the population size and generation of bat the fitness value with minimum frequency is found that helps to avoid convergence among UAV. Finally the evaluation which gives minimum frequency is considered as optimal solution.
\end{abstract}

Keywords: Bat algorithm, Unmanned Aerial Vehicle, Population, Path planning, Frequency, Position.

\section{INTRODUCTION}

$\mathrm{U}$ nmanned Aerial Vehicle (UAV) is shortly called military aircraft. This mainly used in war and during disaster situation and also helps in weather monitoring [1,2]. UAV system important requirements are autonomous exploration and direction [3]. Generally the initial and destination position is needed to plan the path[4] and also it helps to avoid crash and obstacles. Various algorithm are used to solve UAV problem[5,6] such as particle swarm optimization algorithm [7], ant colony optimization algorithm [8], pigeon-inspired optimization algorithm (PIO) [9], fruit fly optimization algorithm (FOA) [10].

The PSO is otherwise called as random search algorithm which helps in solving UAV path planning [11]. By updating the parameters in hybrid PSO, the accuracy rate in UAV path planning is defined. The ACO algorithm is based on ant colony behaviour to optimize path planning problems [12]. ACO commonly needs number of calculations. The direction and chaotic theory are practiced in ACO for improvement. ADD ON algorithm also applied to solve multi objective problems [13]. PIO is swarm intelligence optimization algorithm. SIOA is motivated by pigeon behaviour. This PIO has two operators one is design and circuit operator and second is memorial operator [14]. PIO WITH QUANTUM BEHAVED

Revised Manuscript Received on May 15, 2020.

* Correspondence Author

S. Aicevarya Devi, Mathematics division, School of Advanced Science, Vellore Institute of Technology, Chennai, Tamil Nadu.

Email: aicevaryadevi.s2019@vitstudent.ac.in

C. Vijayalakshmi*, Mathematics division, School of Advanced Science, Vellore Institute of Technology, Chennai, Tamil Nadu. Email: vijayalakshmi.c@vit.ac.in

(c) The Authors. Published by Blue Eyes Intelligence Engineering and Sciences Publication (BEIESP). This is an open access article under the CC BY-NC-ND license (http://creativecommons.org/licenses/by-nc-nd/4.0/)
THEORY PERFORM IN UAV PATH PLANNING. THIS PAPER INCLUDES THE UAV PATH PLANNING PROBLEM MANAGEMENT AND PROPOSED BAT ALGORITHM IN UAV PATH PLANNING. with quantum behaved theory perform in UAV path planning.

This paper includes the UAV path planning problem management and proposed bat algorithm in UAV path planning.

\section{MATHEMATICAL MODEL FORMULATION}

$\boldsymbol{\alpha}$ Euler angles

$\boldsymbol{\beta}$ Angular angles

$\mathrm{X}$ Position

Y Linear velocity

$x_{t}, y_{t}, z_{t}$ Position coordinates

$r_{t}$ Radius

$k_{t}$ Threat level

J Cost function

$I_{l}$ Path length

$I_{a}$ Altitude

$I_{t}$ Threat cost

$l_{i}$ Length above sea level

$h_{i}$ Height above sea level

$Q$ Frequency of bat

$Q_{i}$ Current frequency of bat

$Q_{\min }$ Minimum frequency of bat

$Q_{\max }$ Maximum frequency of bat

$s$ Velocity of bat

$s_{i}^{t}$ Current Velocity of bat

$s_{i}^{t-1}$ Previous Velocity of bat

$g$ Position of bat

$g_{i}$ Current position of bat

$g_{i}^{t-1}$ Previous position of bat

$N_{-}$iter Number of evaluation

$n$ Population size

$A$ Loudness

$d$ Dimension

C Random value

\section{UNMANNED AERIAL VEHICLE}

As per the record in July 1849 UAV is used for war fighting[15]. The UAV arose because of U.S Airforce efforts[16]. Unmanned Aerial Vehicle need short and secure path planning from initial to destination position. All obstacles and danger zone are taken into account and also

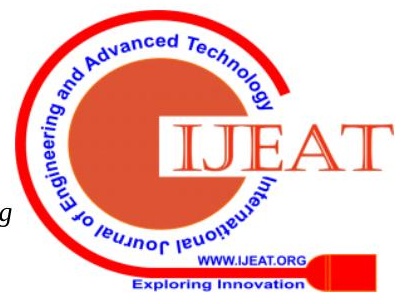


altitude changes and fly speed are needed.

UAV dynamic and UAV threats are constraints with mixed objective optimization problem used for path planning. Consider the UAVs satisfy upcoming dynamics.

$$
\left[\begin{array}{c}
\dot{x} \\
\dot{y} \\
\dot{z}
\end{array}\right]=\left[\begin{array}{l}
v \cos \phi-w \sin \phi \\
u+(w+\cos \phi+v \sin \phi) \tan \theta \\
\frac{1}{\cos \theta}(w \cos \phi+v \sin \phi)
\end{array}\right]
$$

$$
\left[\begin{array}{l}
\dot{p} \\
\dot{q} \\
\dot{r}
\end{array}\right]=\left[\begin{array}{l}
a \cos \phi \cos \psi+b(\sin \phi \sin \theta \cos \psi- \\
\cos \phi \sin \psi)+c(\sin \phi \sin \psi+ \\
\cos \phi \sin \theta \cos \psi) \\
a \cos \phi \cos \psi+b(\sin \phi \sin \theta \cos \psi+ \\
\cos \phi \sin \psi)+c(-\sin \phi \sin \psi+ \\
\cos \phi \sin \theta \cos \psi) \\
a \sin \theta-b \sin \theta \cos \theta-c \cos \phi \cos \theta
\end{array}\right]
$$

Then $\alpha=[x y z]$ are Euler angles, $\beta=[u v w]$ are Zigzag angles, $X=[p q r]$ are posture, $Y=[a b c]$ are linear velocity.

Next to calculate the threats in the circumstances the radius $r_{t y}$ position coordinates $\left(x_{t}, y_{t}, z_{t}\right)$ and threat level $k_{t}$. It includes length, time and security element. The successive optimization problem helps to solve UAV path planning.

$$
\min I=i_{1} I_{l}+i_{2} I_{k}+i_{3} I_{m} i_{1}+i_{2}+i_{3}=1
$$

where $I_{m}, I_{l}$ and $I_{k}$ are the cost function which indicates altitude cost, path length cost and threat cost.

The altitude cost is measured by $I_{m}=\sum_{j=1}^{n} h_{j}$

The path length cost is measured by $I_{l}=\sum_{j=1}^{n} l_{j}^{2}$

where $h_{j}$ and $l_{i}$ are height and length over the sea level.

The threat cost is measured by 4 points and these points have connecting edges between two points.

$$
I_{k}=\frac{A_{m n}}{4} \sum_{t=1}^{N_{t}} k_{t}\left(\frac{1}{f_{0.1, t}^{4}}+\frac{1}{f_{0.3, t}^{4}}+\frac{1}{f_{0.5, t}^{4}}+\frac{1}{f_{0.7, t}^{4}}\right)
$$

where $f_{(0.1, t)}$ is the breadth between $1 / 10$ and $\mathrm{t}$ - threat core.

\section{BAT ALGORITHM}

Bat algorithm was first proposed by Xin-She Yang [17][18]. This algorithm is based on bats behaviour[19]. The main behaviour of bat is echolocation that helps to predict the difference between prey and obstacles. It has 3 rules.
Rule 1: Echolocation used to sense the distance and helps to identify difference between food and prey.

Rule 2: Bat fly at random with velocity $v_{i}$ at position $X_{i}$ with different frequency ranges $f[\mathrm{~min}, \max ]$ varying wavelength $\lambda$ and loudness $A$ to look for prey. It naturally contain the emitted pulses.

Rule 3: Loudness differ from large value to minimum constant value $\left[A_{0}\right.$ to $\left.A_{\text {min }}\right]$.

Frequency ranges between maximum to minimum or it is called as frequency-tuning algorithm. Every bat correlate with velocity $s_{i}^{t}$ and position $g_{i}^{t}$ in search space at each iteration t with respect to frequency $Q_{i}$. So in every iteration the frequency, the position and the speed updating is needed.

TO CALCULATE THE FREQUENCY OF BAT

$Q_{i}=Q_{\min }+\left(Q_{\max }-Q_{\min }\right) C$

TO CALCULATE VELOCITY OF BAT

$s_{i}^{t}=s_{i}^{(t-1)}+\left(g_{i}^{(t-1)}-g_{*}\right) Q_{i}$

\section{TO CALCULATE POSITION OF BAT}

$g_{i}=g_{i}^{(t-1)}+s_{i}^{t}$

\section{A. Procedure to Plan Route for UAV Using Bat Algorithm}

Step 1: Initialize bat population, its position, velocities and frequency of all bats.

Step 2: Initialize Echolocation of all bats.

Step 3: Evaluating micro-bats in initial position, the calculated solutions are stored in resource log.

Step 4: Arrange the current population in downward order. Step 5: Develop candidate micro-bats.

Step 6: Irregular flying by adjusting new position, velocity and direction.

Step 7: Inconstantly choose a micro-bat from population.

Step 8: Evaluate micro-bat by fitness function.

Step 9: For upcoming position echolocation parameters is updated.

Step 10: Select the fittest micro-bat for next iteration.

Step 11: Until reach the expectation criterion rerun the process from step 4 to step 10 .

\section{B. General Algorithm}

\{initialize bat population, its position, velocity and frequency\}

Initialize population of bat $x_{i}(i=1,2, \ldots, n)$ and $s_{i}$

Determine pulse frequency $f_{i}$ at $x_{i}$

Define heart rate $r_{i}$ and loudness $A_{i}$

while $t<$ Maximum number of repetition)

Provoke new explanation by modifying frequency and updating velocities and position

if(rand $r$ )

Single out the solution amid finest solution

Generate local

Published By: 
solution over the elected best solution

end if

Develop new solution randomly

Test the fitness of new solution w.r.t $r$ and $A$ Obtain the new solution

Extend $r_{i}$ and cut down $A_{i}$

end if

Grade the bats and find the current $X_{*}$

end while

To calculate the minimum frequency MATLAB software is used and the number of evaluation taken from 100 to 4000 under dimension one.

\begin{tabular}{|c|c|c|}
\hline $\begin{array}{l}\text { Number of } \\
\text { Evaluation }\end{array}$ & BEST & fmin \\
\hline 100 & -0.1115 & 0.012433 \\
\hline 200 & $-1.3354 \mathrm{e}-05$ & $1.7834 \mathrm{e}-10$ \\
\hline 300 & $-6.1153 e-06$ & $3.7396 \mathrm{e}-11$ \\
\hline 400 & $-7.2749 \mathrm{e}-06$ & $5.2923 \mathrm{e}-11$ \\
\hline 500 & $2.2173 \mathrm{e}-06$ & $4.9165 \mathrm{e}-12$ \\
\hline 600 & $1.2309 \mathrm{e}-06$ & $1.5152 \mathrm{e}-12$ \\
\hline 700 & $1.8205 \mathrm{e}-06$ & $3.3143 \mathrm{e}-12$ \\
\hline 800 & $-1.3192 \mathrm{e}-06$ & $1.7403 \mathrm{e}-12$ \\
\hline 900 & $-3.883 e-06$ & $1.5077 \mathrm{e}-11$ \\
\hline 1000 & $1.1005 \mathrm{e}-07$ & $1.211 \mathrm{e}-14$ \\
\hline 1100 & $4.0589 \mathrm{e}-06$ & $1.6475 \mathrm{e}-11$ \\
\hline 1200 & $-2.9884 \mathrm{e}-05$ & $8.9304 \mathrm{e}-10$ \\
\hline 1300 & $-2.4258 \mathrm{e}-06$ & $5.8844 \mathrm{e}-12$ \\
\hline 1400 & 7.8483e-07 & $6.1596 \mathrm{e}-13$ \\
\hline 1500 & $-3.0766 \mathrm{e}-06$ & $9.4657 \mathrm{e}-12$ \\
\hline 1600 & $-2.0164 \mathrm{e}-06$ & $4.066 \mathrm{e}-12$ \\
\hline 1700 & $-7.0061 \mathrm{e}-07$ & $4.9085 \mathrm{e}-13$ \\
\hline 1800 & $-1.3412 \mathrm{e}-07$ & $1.7989 \mathrm{e}-14$ \\
\hline 1900 & $-1.0088 \mathrm{e}-06$ & $1.0176 \mathrm{e}-12$ \\
\hline 2000 & $-3.7082 \mathrm{e}-07$ & $1.3751 \mathrm{e}-13$ \\
\hline 2100 & $-4.6404 \mathrm{e}-07$ & $2.1533 \mathrm{e}-13$ \\
\hline 2200 & $-2.2475 \mathrm{e}-06$ & $5.0513 \mathrm{e}-12$ \\
\hline 2300 & $2.4211 \mathrm{e}-06$ & $5.8617 \mathrm{e}-12$ \\
\hline 2400 & $1.5787 \mathrm{e}-06$ & $2.4922 \mathrm{e}-12$ \\
\hline 2500 & $2.0714 \mathrm{e}-06$ & $4.2905 \mathrm{e}-12$ \\
\hline 2600 & $2.3484 \mathrm{e}-06$ & $5.5151 \mathrm{e}-12$ \\
\hline 2700 & $1.4283 \mathrm{e}-06$ & $2.0402 \mathrm{e}-12$ \\
\hline 2800 & 8.1923e-07 & $6.7114 \mathrm{e}-13$ \\
\hline 2900 & $-8.4173 e-07$ & $7.0851 \mathrm{e}-13$ \\
\hline 3000 & $4.5351 \mathrm{e}-07$ & $2.0567 \mathrm{e}-13$ \\
\hline 3100 & $-7.0359 \mathrm{e}-07$ & $4.9503 \mathrm{e}-13$ \\
\hline 3200 & $7.0965 \mathrm{e}-07$ & $5.036 \mathrm{e}-13$ \\
\hline 3300 & $2.3062 \mathrm{e}-07$ & $5.3184 \mathrm{e}-14$ \\
\hline 3400 & $-2.0333 e-06$ & $4.1343 e-12$ \\
\hline 3500 & $2.06 \mathrm{e}-07$ & $4.2436 \mathrm{e}-14$ \\
\hline 3600 & $-9.9604 \mathrm{e}-07$ & $9.921 \mathrm{e}-13$ \\
\hline 3700 & $1.642 \mathrm{e}-07$ & $2.6961 \mathrm{e}-14$ \\
\hline 3800 & $-2.9269 \mathrm{e}-07$ & $8.5668 \mathrm{e}-14$ \\
\hline $\begin{array}{l}\text { Number of } \\
\text { Evaluation }\end{array}$ & \multicolumn{2}{|c|}{ BEST } \\
\hline 3900 & \multicolumn{2}{|c|}{$-3.4921 \mathrm{e}-07$} \\
\hline 4000 & $-5.0015 e-07$ & 2.50 \\
\hline
\end{tabular}

Published By:

Blue Eyes Intelligence Engineering

\& Sciences Publication

(C) Copyright: All rights reserved. algorithms. minimum time.

\section{REFERENCES} 5429-5436 or aerial drones: A survey Networks 2018, 1-48. Trans. Robot. 2015, 31, 1130-1146. 28, 14-28. 735-753. 2017, 15, 1-16. 69-74 2017, 25, 122-158. Algorithm. Chin. J. Aeronaut. 2005, 18, 18-23. Cybern. 2014, 7, 24-37. page 355. 978-0-8168-6654-0. evaluated from 100 to 4000 and in $1000^{\text {th }}$ evaluation best fitness value is found with the minimum frequency which gives best path for UAV. In this paper one dimension calculation is manipulated even it can extend to $n$ dimensions whereas this extension of dimension is not applicable in other

\section{CONCLUSION}

To forbid quick loss and numerical incomplete concurrence at few native optimum, a replacement community change approach was bestowed concerning these problems. Comparing with other algorithms bat algorithm is flexible, easy to understand and gives best solution in

1. Tisdale, J.; Kim, Z.; Hedrick, J.K. Autonomous UAV path planning an estimation. IEEE Robot. Autom. Mag. 2009,61, 35-42.

2. Trotta, A.; D'Andreagiovanni, F.; Felice, M.; Natalizio, E. Chowdhury, K. When UAVs ride a bus: Towards Energy-efficiency City-scale Video Surveillance. In proceedings of the IEEE Conference on Computer Communications, Honolulu, HI, USA, 15-19 April 2018.

3. Zhang, Y.;Li, S. Distributed Biased Min-Consensus with Applications to Shortest Path Planning. IEEE Trans. Autom. Control 2017, 62,

4. Otto, A.; Agatz. N.; Cambell, J.; Golden, B.; Pesch, E. Optimization approaches for civil applications of unmanned aerial vechicles(UAVs)

5. Yang, P.; Tang, K.; Lozano, J.A.; Gao, X. Path Planning for Single Unmanned Aerial Vehicle by Separately Evolving Waypoints. IEEE

6. Das, P.K.; Behera, H.S.; Panigrahi, B.K. Ahybridization of an improved particle swarm optimization and gravitational search algorithm for multi-robot path planning. Swarm Evol. Comput. 2016

7. Das, P.K.; Behera, H.S.; Das, S.; Tripathy, H.K.; Panigrahi, B.K.; Pradhan, S.K. A hybrid improved PSO-DV algorithm for multi-robo path planning in a clutter Environment. Neurocomputing 2016, 207,

8. Lee, J. Heterogeneous-ants-based path planner for global path planning of mobile robot applications. Int. J. Control Autom. Syst.

9. Duan, H.; Ye, F. Progresses in Pigeon-inspired Optimization Algorithms. J. Beijing Univ. Technol. 2017, 43, 1-7.

10. Pan. W.T. Anew Fruit Fly Optimization Algorithm: Taking the financial distress model as an example. Knowl. Based Syst. 2012, 26 ,

11. Masdari, M.; Salehi, F.; Jalali, M.; Bidaki, M. A Survey of PSO-Based Scheduling Algorithms in Cloud Computing. J. Netw. Syst. Manag.

12. Wen, Y.E.; Deng-Wu, M.A; Fan, H.D. Algorithm for Low Altitude Penetration Aircraft Path Planning with Improved Ant Colony

13. Bharathi, K. and Vijayalakshmi, C. Multi-Objective Transportation Problem Using Add On Algorithm, International Journal of Pure and Applied Mathematics, Scopis 2017, Volume 109 No. 10 2016, 99-107.

14. Duan, H.; Qiao, P. Pigeon-inspired Optimization: A new swarm intelligence optimizer for air robot path planning. Int. J. Intell. Comput.

15. The Future of Drone Use: Opportunities and Threats from Ethical and Legal Perspectives, Asser Press - Springer, chapter by Alan McKenna,

16. Wagner, William (1982), Lighting Bugs and other Reconnaissance Drones; The can-do story of Ryan's unmanned spy planes, Armed Forces Journal International: Aero Publishers, ISBN

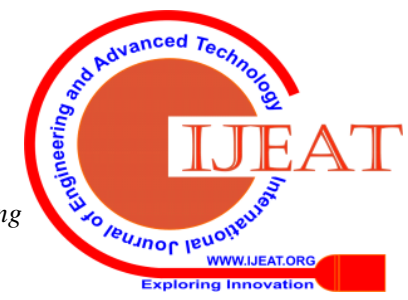


17. Yang, X. S. (2010). "A New Metaheristic Bat-Inspired Algorithm, in: Nature Inspired Cooperative Strategies for Optimization (NISCO 2010)". Studies in Computational Intelligence. 284: 65-74.

18. Yang, X. S., Nature-Inspired Metaheuristic Algorithms, 2nd Edition, Luniver Press, (2010).

19. Tsai, P. W.; Pan, J. S.; Liao, B. Y.; Tsai, M. J.; Istanda, V. (2012). "Bat algorithm inspired algorithm for solving numerical optimization problems". Applied Mechanics and Materials. 148-149: 134-137.

\section{AUTHORS PROFILE}

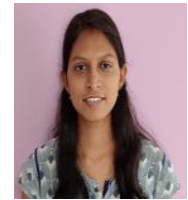

S. Aicevarya Devi, Research Scholar in the Division of Mathematics, School of Advanced Sciences, Vellore Institute of Technology, Chennai. Completed the under graduation and post graduation in Mathematics under Madras University affiliated colleges. Published a paper 'Diasater Management Using Bio Inspired Algorithms' which is about how Bio Inspired Algorithms plays role on disaster management and have interest in Optimization Techniques, Bio Inspired Algorithms and also in real term challenging application problems regarding Bio Inspired. Got a certificate for completion of LATEX Training from IIT Bombay. Presented a paper on comparative analysis of Bio Inspired Algorithms in $9^{\text {th }}$ World Engineering Education Forum (WEEF).

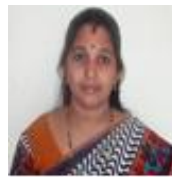

Dr.C.Vijayalakshmi, is working as Professor in the Division of Mathematics, School of Advanced Sciences, Vellore Institute of Technology, Chennai. She has 25 years of teaching experience and 2 years of Industrial experience. She has authored four books for Engineering Students. She has published 102 papers in International and National Scopus indexed Journals. Sixteen Scholars were awarded Ph.D under her supervision. She has organized International workshops with CSIR funding. She has completed two projects. She has guided PG students for their projects. Guest editor for International Journal of Computer Aided Technology. Her interest includes Optimization Techniques, Statistics, Data analysis, Stochastic Processes and Bulk Queueing models Machine Learning Algorithms, Fuzzy Optimization Techniques. 